\title{
DESENVOLVIMENTO E AVALIAÇÃO DE UM OBJETO DE APRENDIZAGEM SOBRE O CUSTO DO BANHO PARA ENSINO DE FÍSICA*
}

\author{
Iuri Medeiros Jauris - Curso de Física - UNIFRA, Santa Maria - RS (iuri.jauris@gmail.com) \\ Solange B. Fagan - Curso de Física - UNIFRA, Santa Maria - RS (sfagan@unifra.br) \\ Antônio Vicente L. Porto - Curso de Física - UNIFRA, Santa Maria - RS (porto@unifra.br)
}

\section{RESUMO}

Este trabalho apresenta as experiências obtidas por docentes e discentes da UNIFRA na produção e aplicação de objetos de aprendizagem interativos desenvolvidos segundo a metodologia RIVED, Rede Interativa Virtual de Educação, para a área de física. O material didático "Custo do Banho" foi desenvolvido com recursos pedagógicos, de conteúdo e de tecnologias multimídias e tem demonstrado ser uma ferramenta interessante para subsidiar o entendimento de quantidades físicas como vazão e potência elétrica calculando o custo de um banho.

Palavras-chave: objetos de aprendizagem, interatividade, ensino de física.

DEVELOPMENT AND EVALUATION OF LEARNING OBJECT ABOUT THE BATH COST FOR PHYSICS EDUCATION

\section{ABSTRACT}

This work presents the experiences obtained through the production and application of a learning object in physics subjects following the RIVED, virtual interactive network of education, methodology. The learning object is associated with the "Bath Cost" using multimedia resources, pedagogic methodologies and physics subject as electrical potential and water flow. This educational material was applied in a physics graduation class of the UNIFRA University.

\footnotetext{
* Projeto financiado pela SEED/ MEC, convênio UFSM - UNIFRA

V. 6 № 1, Julho, 2008
} 


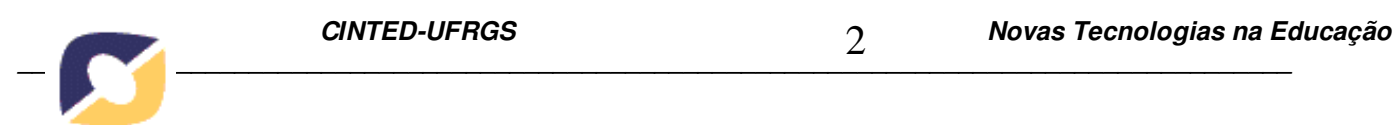

Key-words: learning objects, interactivity, physics learning INTRODUÇÃO

Atualmente compreendemos que o fácil acesso aos computadores e a internet gera uma nova dimensão para o uso de softwares educativos no processo de ensino-aprendizagem. A interatividade dos objetos virtuais proporciona aos alunos serem autores de suas aprendizagens, fazendo com que cada um aprenda ao seu ritmo [NASCIMENTO, 2005].

A sala de aula tem sido tradicionalmente um momento de discussão, muitas vezes, frustrado, devido à passividade dos alunos e ao uso, por parte dos professores, de recursos de ensino tradicionais sem a interação com novas tecnologias. Desta forma, o uso dos recursos de novas tecnologias no ensino, principalmente ensino de ciências, tem sido vislumbrado por pesquisadores como uma forma alternativa de fomentar a interação professor-aluno na sala de aula, assim como estudos extra classe [PIRES e VEIT, 2006].

Paralelamente a esta discussão, a Rede Virtual de Educação, RIVED, do Ministério da Educação e Cultura, MEC, tem estimulado a elaboração de objetos de aprendizagem pelas diversas equipes de professores e alunos das universidades brasileiras, tendo sempre como objetivo a melhoria do processo de ensino-aprendizagem das diferentes áreas de conhecimento. A metodologia proposta pelo RIVED prevê o desenvolvimento de objetos de aprendizagem que tenham o intuito de abranger temas que transcendam a sala de aula, sendo reutilizáveis dentro de vários ambientes de aprendizagem. Nascimento (2005) considera que qualquer conteúdo eletrônico contendo informações que auxiliem no processo ensino-aprendizagem pode ser considerado objeto de aprendizagem.

Estudos recentes têm mostrado que os objetos de aprendizagem podem ser uma alternativa pedagógica eficaz no ensino de conteúdos para disciplinas da educação básica [PIRES e VEIT, 2006]. Estes objetos fazem com que o aluno pense, questione-se e busque as respostas para suas dúvidas em temas relacionados, muitas vezes, com o seu dia-a-dia. Nesse sentido, o aluno desfruta da atividade prazerosa de buscar a resposta e analisar os resultados dos problemas com o auxílio da tecnologia. Portanto, o aluno pode construir seu percurso próprio de aprendizagem em experiências de interação com a máquina, de acordo com seu conhecimento sobre o assunto. 


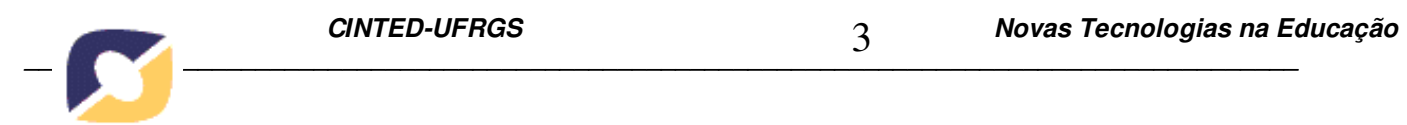

Dentro desse contexto, o Centro Universitário Franciscano (UNIFRA) tem desenvolvido pesquisas para produção e avaliação de conteúdos educacionais digitais a serem utilizados em diversas situações de aprendizagem, tanto por professores quanto por alunos (www.unifra.br/rived). Desta forma, o grupo RIVED da área de física da UNIFRA desenvolveu em 2007 um objeto de aprendizagem sobre o "Custo do Banho", enfatizando conteúdos como vazão e potência elétrica. Este material didático foi aplicado a uma turma de alunos do primeiro semestre do curso de Física Bacharelado da UNIFRA em abril de 2008.

\section{METODOLOGIA}

\section{- Produção do objeto de aprendizagem: Custo do Banho}

A UNIFRA conta, atualmente, com um grupo de capacitação, avaliação e produção de objetos de aprendizagem fazendo uso da metodologia RIVED. Esse grupo, composto por alunos de graduação, pós-graduação e professores, busca uma intensa integração entre diferentes áreas do conhecimento e equipes técnicas.

Neste caso, em particular, o tema proposto pelo grupo de trabalhos da física para desenvolvimento do objeto de aprendizagem foi o "Custo do Banho". Esse tema foi proposto por englobar diversos conteúdos estudados pelos alunos do ensino médio e superior, e por possibilitar uma fácil contextualização com o cotidiano do aluno. A equipe do curso de física foi formada por dois professores, orientadores, dois bolsistas e quatro voluntários que desenvolveram, conjuntamente, dois objetos de aprendizagem.

O objeto "Custo do Banho" explora alguns conceitos básicos da física, como potencia elétrica, vazão, trabalho, e faz uma relação desses conteúdos com o cotidiano do aluno. Para o desenvolvimento do objeto de aprendizagem foram seguidos os seguintes procedimentos:

(i) organização de um design pedagógico pelas equipes técnica, de conteúdo e pedagógica;

(ii) realização de um roteiro com os conteúdos e atividades a serem desenvolvidos;

(iii) produção do objeto de aprendizagem pela equipe técnica com supervisão da equipe pedagógica e de conteúdo. O objeto de aprendizagem foi construído com base no software Macromedia Flash, sendo que a equipe técnica levou em consideração a orientação do grupo responsável pela parte pedagógica e as informações descritas no roteiro. 


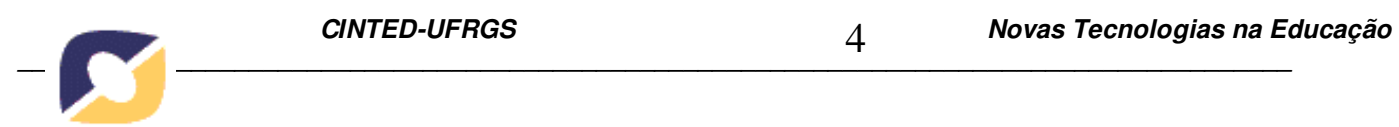

(iv) desenvolvimento do guia do professor com sugestões sobre o uso do objeto e atividades.

\section{- Aplicação e avaliação do objeto de aprendizagem: Custo do Banho}

Após a produção do objeto de aprendizagem a equipe passou para a segunda etapa do trabalho onde o material instrucional desenvolvido foi aplicado em uma turma do primeiro semestre do curso de Física Bacharelado da UNIFRA. O objeto foi aplicado em dois períodos de 50 min de aula juntamente com questões avaliativas. A turma foi composta por 16 alunos distribuídos em duplas, ou seja, oito (08) grupos. A metodologia adotada foi dividida em três etapas:

(i) Inicialmente os alunos tiveram 15 min para responder a um pré-teste com as seguintes questões:

- Você sabe o custo médio da energia elétrica e da água utilizada durante um banho de chuveiro elétrico?

- Qual a unidade utilizada pela companhia de distribuição de energia elétrica para cobrar o consumo de energia elétrica?

- Qual a unidade utilizada pela companhia de distribuição de água tratada para cobrar o consumo da mesma?

- Estime o tempo de duração do seu banho.

- Quantas opções de potência para aquecimento de água têm seu chuveiro e quais destas vocês usam habitualmente?

- Qual a relação entre potência elétrica e energia elétrica?

- Com a torneira aberta durante o banho, você tem noção da quantidade de água utilizada?

Avalie quantos litros você normalmente usa durante um banho.

- Qual o significado físico de vazão?

- Você sabe o custo total de seu banho?

(ii) Na segunda etapa os grupos participantes realizaram as atividades do objeto de aprendizagem “Custo do Banho", fazendo no mínimo quatro (04) tentativas de diferentes tipos de banhos.

(iii) Após a manipulação do objeto de aprendizagem os alunos responderam ao pós-teste, o qual era composto das seguintes questões, algumas repetidas a partir do pré-teste: 


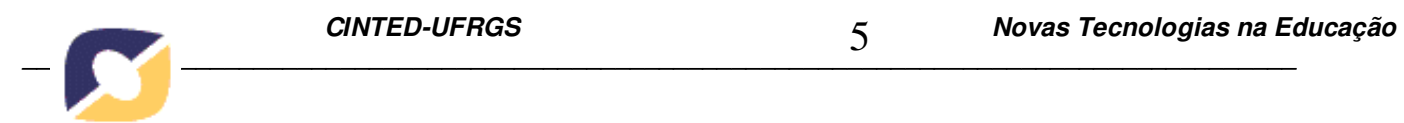

- Você sabe qual o custo da energia elétrica e a água utilizada durante um banho de chuveiro elétrico?

- Qual a unidade utilizada pelas companhias de energia elétrica e de distribuição de água para cobrar o consumo?

- Qual a relação entre potência e energia elétrica?

- Qual o significado de Vazão?

- Você sabe calcular o custo de seu banho?

- Você encontrou dificuldades em navegar o software?Quais?

- As questões do objeto estão postas de forma clara e objetiva?

- Você acha que o objeto poderia fornecer alguma informação, textos, instruções etc, a mais? Quais?

- Você considera que a exposição de conteúdos usando o computador, como neste caso, facilita na compreensão dos conteúdos?

A seguir apresentamos as discussões sobre a produção e avaliação do objeto de aprendizagem o custo do banho.

\section{DISCUSSÕES}

As discussões serão apresentadas em duas etapas, a primeira envolvendo a descrição do objeto e a segunda mostrando os resultados da aplicação e avaliação do material instrucional.

\section{- Objeto Custo do Banho}

O objeto de aprendizagem o custo do banho tem por objetivos:

- Calcular o custo do banho utilizando os conceitos aprendidos em sala de aula, mostrando a aplicação no cotidiano dos alunos;

- Conscientizar os alunos sobre o uso racional da energia elétrica e água, reduzindo o tempo consumido durante o banho economizando nas faturas de luz e água.

Para atingir estes objetivos, o objeto foi organizado de forma a envolver o aluno na atividade desde a tela inicial, a qual faz o convite para a realização da atividade, conforme mostra a Figura 1. 


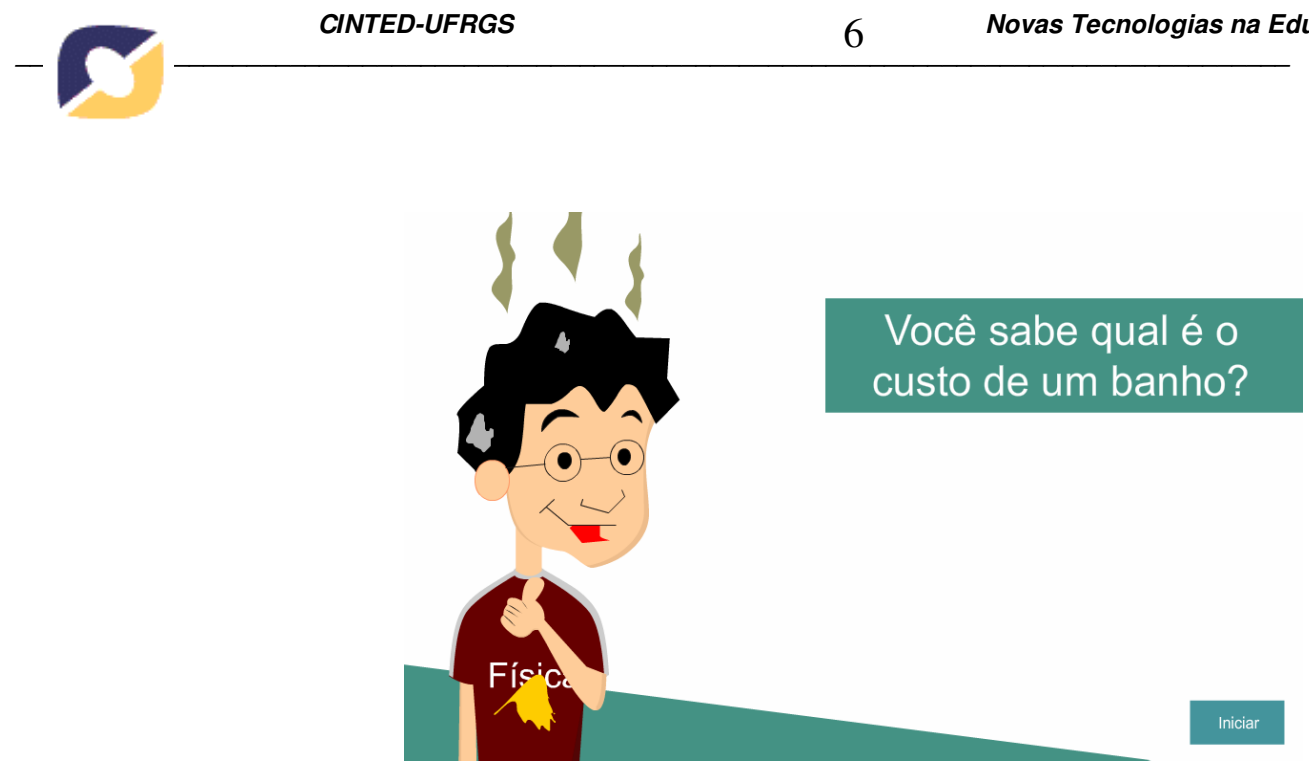

Figura 1: Tela inicial do objeto "Custo do Banho".

Após, o aluno entra em contato com uma tela que contém instruções (Figura 2), assim como objetos como chuveiro, torneira e relógio. Nesta tela podem-se variar parâmetros como potência elétrica do chuveiro, vazão, tempo de banho e que serão utilizados para calcular o custo total do banho na etapa seguinte. Esta tela conta ainda com uma janela de instrução sobre conteúdos no botão "saiba mais", que conduz a explicações mais detalhadas sobre os conceitos envolvidos no objeto.

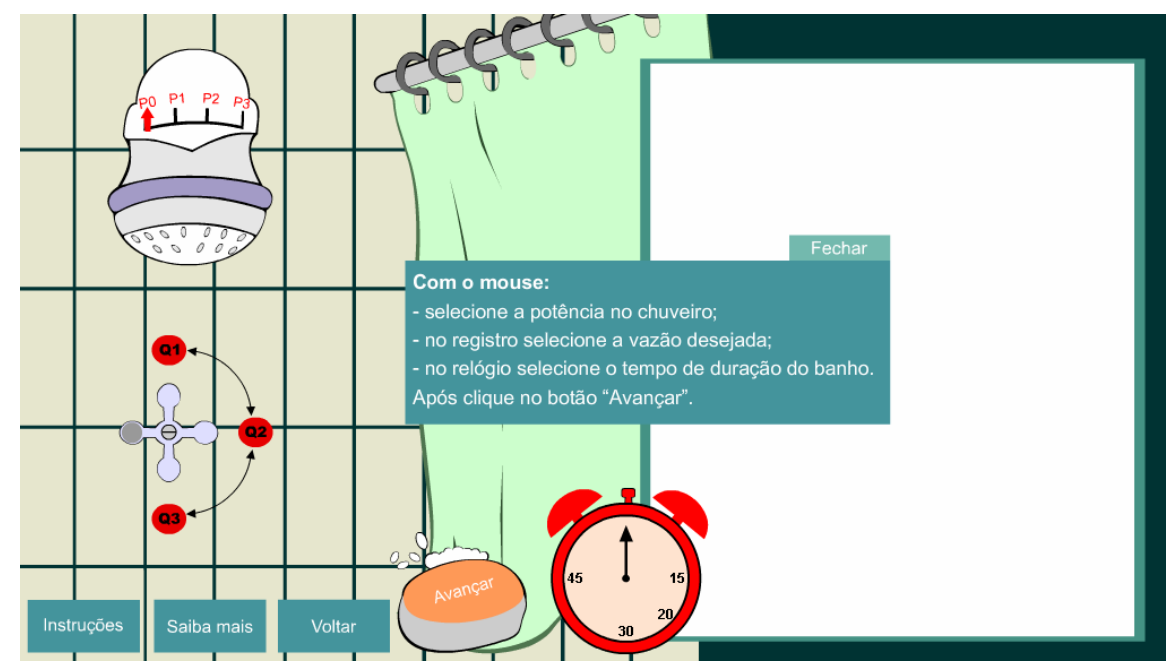

Figura 2: Tela da escolha das variáveis utilizadas no decorrer da atividade.

Após selecionar os parâmetros para o cálculo do custo do banho, na etapa seguinte o aluno deve calcular o custo referente à energia elétrica e a água, utilizados no banho em um determinado tempo (Figura 3(a)). Assim o aluno chegará ao valor do custo total deste banho fazendo uso, se V. 6 № 1 , Julho, 2008 
necessário, de uma calculadora para facilitar a obtenção dos resultados das operações por parte dos alunos e também o link "saiba mais”, para possíveis dúvidas.

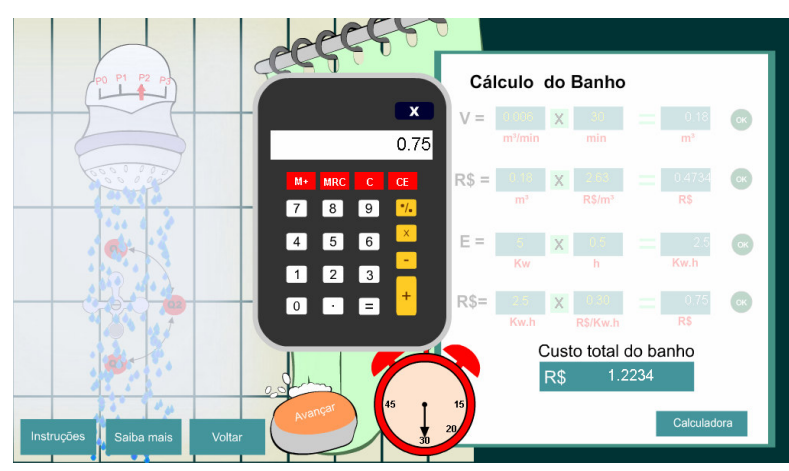

(a)

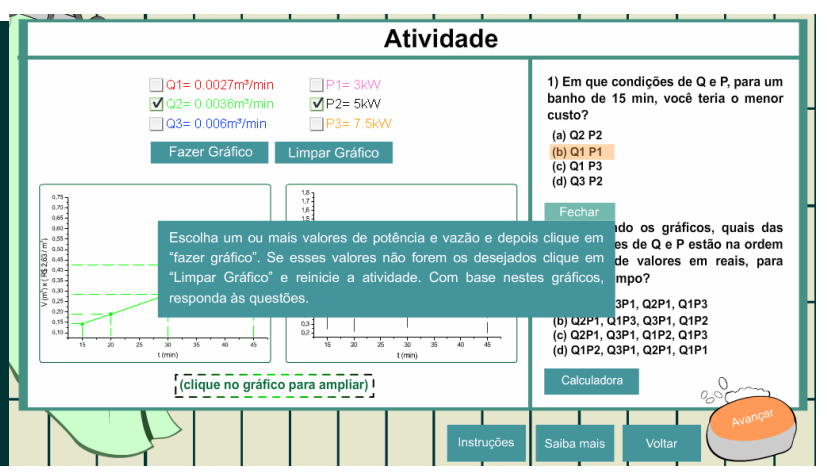

(b)

Figura 3: Calculando o custo total do banho e atividades referentes ao custo do banho fazendo uso de gráficos.

Após o cálculo correto do custo do banho, o aprendiz terá contato com outras atividades, com mostra a Figura 3(b). Nesta etapa é possível fazer uma avaliação das relações entre potência, vazão, tempo e custo do banho fazendo uso de gráficos. Esta atividade conta ainda com duas questões de compreensão sobre o objeto e um link "saiba mais", para possíveis dúvidas do aluno.

Finalmente o aluno poderá alcançar a tela final (Figura 5). Vale ressaltar que o aluno somente chegará até esta etapa se realizar corretamente todas as atividades anteriores. No caso de dificuldade, a própria atividade auxilia na compreensão dos erros cometidos, pois são apresentadas as possíveis soluções e a forma como obtê-las, não permitindo que o aluno desista da atividade.

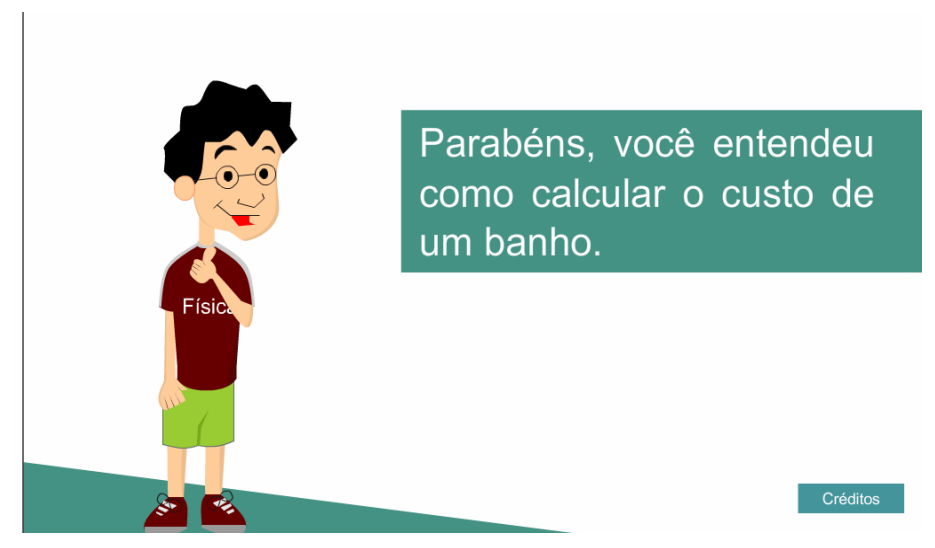

Figura 5: Tela referente à finalização do objeto de aprendizagem. 


\section{- Avaliação do Material Instrucional}

Discutiremos a seguir os principais resultados observados a partir da aplicação do objeto de aprendizagem aos alunos do curso de Física da UNIFRA. A escolha desta turma está associada ao fato dos alunos serem calouros do curso, possibilitando com isto uma avaliação em alunos advindos do terceiro ano do ensino médio, onde já deveriam ter os conceitos de potência elétrica e vazão bem estabelecidos.

Segundo Ausubel (1980-2003) o aprendiz organiza hierarquicamente o conhecimento e dessa forma a aprendizagem é significativa, considerando desta forma prioritariamente as idéias mais inclusivas e posteriormente as idéias subordinadas ou específicas. Muitas vezes pode-se aprender algo mecanicamente e só mais tarde perceber que este se relaciona com algum conhecimento anterior já dominado, a "âncora", também chamado conceito subsunçor. O objeto de aprendizagem "Custo do Banho" foi construído usando como referencial teórico as teorias de Ausubel fazendo uso de uma ampla contextualização (MOREIRA, 2002). Esse objeto requer do aprendiz subsunçores desenvolvidos em conteúdos programáticos do segundo e terceiro ano do ensino médio na área de física. Considera-se também o contexto do banho diário e consciência ecológica e financeira do ato banho.

Conforme definido na metodologia os alunos foram divididos em oito (08) grupos que participaram de três etapas durante a aplicação do material instrucional, inicialmente o pré-teste, após a aplicação do objeto e finalmente o pós-teste. Também foi utilizado um questionário de satisfação do usuário quanto a facilidade de navegação e interesse no assunto no objeto de aprendizagem.

Sobre as questões de conhecimento específico verificamos que houve um crescimento significativo nas respostas corretas no pós-teste após a aplicação do objeto. Na questão relacionada ao conhecimento da unidade de energia consumida o índice de acerto evoluiu de $25 \%$ no pré-teste para $62 \%$ no pós-teste. Da mesma forma, quando os alunos foram questionados sobre a unidade com a qual a companhia de distribuição de água utiliza para avaliação do consumo 37,5\% responderam corretamente no pré-teste e $62 \%$ no pós-teste, sendo que alguns alunos continuaram fazendo confusão entre as unidades. Sobre as questões conceituais de potência elétrica e energia 


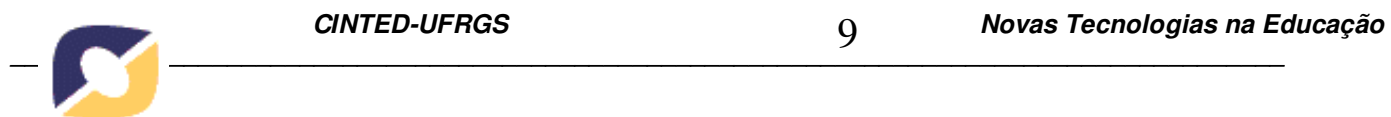

elétrica $12 \%$ dos alunos responderam corretamente o pré-teste, mas após a realização do objeto de aprendizagem o índice de acerto aumentou para 50\%, o que ainda não é um índice satisfatório. Quanto ao conceito de vazão a relação pré/pós-teste evoluiu de 37,5 para 75\%.

O questionário tanto do pré-teste como do pós-teste fazia uma estimativa sobre o custo do banho. Em todos os casos inicialmente o aluno não estimou corretamente estes valores, sendo que após a realização do objeto todos foram capazes de obter um valor razoável, dentro dos valores estimados para potência, vazão e tempo.

Também foram desenvolvidas questões de observação onde o aluno deveria saber quais as opções de potência e vazão do chuveiro utilizado em sua casa e do tempo médio de duração de um banho. Verificou-se que poucos alunos conseguiram fazer a relação dos parâmetros do banho escolhidos com o equipamento utilizado em um banho.

Os alunos também avaliaram o objeto de aprendizagem quanto a sua motivação, navegação, instruções, textos, conceitos e objetivos. Observou-se que todos os grupos aprovaram a abordagem conceitual contextualizada, fazendo uso de novas tecnologias as quais foram utilizadas no objeto "Custo do Banho". Quanto à navegação permitida pelo objeto a maioria dos grupos não encontrou dificuldades.

\section{CONCLUSÕES}

O processo de ensinar e aprender torna-se cada dia mais angustiante para o aluno já que se tem no seu quotidiano tecnologias que despertam fortemente várias formas de obter informações, principalmente do ponto de vista visual. Desta forma, o professor precisa deixar de lado o papel que muitas vezes acaba assumindo, o de simplesmente transmitir informações, permitindo que o seu aluno participe do processo de ensino e que a sala de aula seja um ambiente propício a mudanças. Portanto, o aluno deve ser um sujeito ativo, tendo sua própria opinião, construindo sua própria aprendizagem e propondo suas próprias ferramentas para que seja capaz de enfrentar uma realidade em que o mercado de trabalho e a sociedade estão cada vez mais exigentes e competitivos. Este trabalho, em específico, trata sobre abordagens, via objetos de aprendizagem, buscando fomentar a aproximação do aluno com as novas tecnologias e com o professor. 


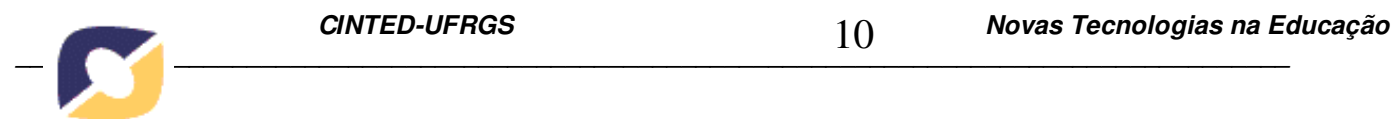

A interatividade aluno-objeto, aluno-aluno e aluno-professor que ocorre quando da exploração de um objeto de aprendizagem em sala de aula permite que se crie uma discussão a respeito das múltiplas relações resultando na obtenção de várias respostas. $\mathrm{O}$ objeto de aprendizagem também pode auxiliar na reflexão sobre as consequiências de um ato quotidiano, como por exemplo, neste caso o custo de um banho mais demorado com o paralelo sobre a agressão ao meio ambiente.

Ressaltando a produção e avaliação do objeto "Custo do Banho" observamos que a relação entre o material instrucional, o professor e o aluno devem ser extremamente próximos. De nada vale um objeto de aprendizagem isoladamente se a reflexão não for permanente. Este fato ficou muito claro nas relações de erro e acerto entre questões pré- e pós-teste durante a aplicação do material instrucional computacional.

Desta forma, a produção de material instrucional fazendo uso de novas tecnologias deve estar fortemente aliada a metodologias que envolvem a reflexão e a discussão entre professor aluno e/ou aluno-aluno, promovendo uma interação sólida e crítica sobre os conteúdos, o dia-a-dia e sobre o papel do próprio material instrucional neste processo de ensino-aprendizagem.

\section{REFERÊNCIAS BIBLIOGRÁFICAS}

PIRES, M. A. e VEIT, E. A. Tecnologias de Informação e Comunicação para ampliar e motivar o aprendizado de Física no Ensino Médio. Revista Brasileira de Ensino de Física, vol. 28, pág. 241, 2006.

MOREIRA, M.A. A teoria dos campos conceituais de Vergnaud, o ensino de ciências e a pesquisa nesta área. Investigações em Ensino de Ciências, vol.7, n.1, mar, 2002.

NASCIMENTO, Anna Christina de Azevedo; Construindo Comunidades de Elaboradores de Objetos de Aprendizagem através de Conteúdo, Tutoria e Interação dos Pares. Secretaria de Educação a Distância, Ministério da Educação, Dez. 2005. Disponível em: < http://rived.proinfo.mec.gov.br/> Acesso em 20 de maio de 2008. 